\title{
DOS PINTURAS DE FRANCISCO BAYEU EN VERGARA
}

\author{
José Ignacio Calvo Ruata ${ }^{1}$ \\ Diputación Provincial de Zaragoza
}

\begin{abstract}
Se presentan dos pinturas inéditas de Francisco Bayeu existentes en la iglesia de Santa Marina de Oxirondo, en Vergara (Guipúzcoa), dedicadas ambas a San Roque y San Sebastián. Son dos versiones del mismo tema por haber tenido que repetirse la obra.

Palabras clave: Francisco Bayeu y Subías; Juan Agustín Ceán Bermúdez; Tomás Jáuregui; Juan Bautista Mendizábal; Santa Marina de Oxirondo; Vergara (Guipúzcoa).
\end{abstract}

\section{TWO PAINTINGS BY FRANCISCO BAYEU IN VERGARA}

Two unpublished paintings by Francisco Bayeu are presented, located in the church of Saint Marina in Oxirondo (Vergara, Guipúzcoa). Both are dedicated to Saint Roch and Saint Sebastian, as they are two versions of the same subject because the work had to be repeated.

Key words: Francisco Bayeu y Subías; Juan Agustín Ceán Bermúdez; Tomás Jáuregui; Juan Bautista Mendizábal; Santa Marina de Oxirondo; Vergara (Guipúzcoa).

Cómo citar este artículo / Citation: Calvo Ruata, José Ignacio (2017): "Dos pinturas de Francisco Bayeu en Vergara". En: Archivo Español de Arte, vol. 90, núm. 359, Madrid, pp. 311-318. doi: 10.3989/aearte.2017.21

Con motivo de la publicación del catálogo de la exposición Goya y Zaragoza, 1746-1775. Sus raices aragonesas se dieron dar a conocer algunas de las breves fichas manuscritas que Ceán Bermúdez fue redactando con la intención de preparar una segunda edición de su famoso diccionario de artistas, que nunca llegó a ver la luz de forma impresa ${ }^{2}$. Unas fichas se conservan en la Biblioteca Nacional de Madrid y otras en la Real Academia de Bellas Artes de San Fernando. Aunque la información que aportan es generalmente poco novedosa, interesa reparar en la dedicada a Francisco Bayeu. Dice así:

Arag. 1780. Bayeu y Subías (D. Francisco), pintor. Vergara. Parroquia de Santa Marina de Orizondo. Dos quadros de un mismo asunto y composición, repetidos por haber salido el primero pequeño para el sitio en que se había de colocar. Ambos representan a San Roque y a San Sebastián. El mayor está en un retablo de la iglesia y el menor en la sacristía.

La noticia fue recogida casi literalmente por el conde la Viñaza, pero desde entonces cayó en el total olvido historiográfico ${ }^{3}$. Indagando en el asunto se puede verificar que, en efecto, Bayeu

1 jicalvo@dpz.es / ORCID iD: http://orcid.org/0000-0001-6182-2989

2 Calvo, 2015: 69.

${ }^{3}$ Archivo de la Real Academia de Bellas Artes de San Fernando, Madrid, leg. 4-88-1, carpeta B, hoja 4. Viñaza, 1889-1894: II, 51. 
pintó para la hoy llamada iglesia de Santa Marina de Oxirondo en Vergara -o Bergara- (Guipúzcoa) dos versiones de un mismo tema dedicado a los santos Roque y Sebastián, obras que siguen permaneciendo allí y que responden a las siguientes especificaciones ${ }^{4}$ :

Francisco Bayeu y Subías (Zaragoza, 1734-Madrid, 1795). San Roque y San Sebastián. $181 \times 119 \mathrm{~cm}$; marco: $204 \times 142 \mathrm{~cm}$. Óleo sobre lienzo. Vergara (Guipúzcoa), iglesia parroquial de Santa Marina de Oxirondo, dependencias parroquiales. Ca. 1757-1758.

Francisco Bayeu y Subías (Zaragoza, 1734-Madrid, 1795). San Roque y San Sebastián. $251 \times 157 \mathrm{~cm}$ (luz del marco). Óleo sobre lienzo. Vergara (Guipúzcoa), iglesia parroquial de Santa Marina de Oxirondo, pintura titular de su retablo en el lado de la Epístola, próximo a la cabecera. Ca. 1757-1758.

\section{Encargos artísticos para la iglesia de Santa Marina en el siglo XVIII}

El exhaustivo estudio sobre el patrimonio religioso de Vergara realizado por M. ${ }^{a}$ José Aramburu no aporta documentación específica sobre estos cuadros, pero permite contextualizar las circunstancias bajo las cuales fueron encargados 5 . Siguiendo a esta autora sabemos que la iglesia de Santa Marina (fig. 1), cuya fábrica había sido iniciada en el siglo XVI, contó en el siglo XVIII con sustanciosos patrocinios para la construcción de varios retablos. El mayor, hecho según traza de Miguel de Irazusta y terminado en 1743, recibió estatuaria de un prestigioso artífice de Madrid que se ha identificado con Luis Salvador Carmona. Colateralmente se colocaron cuatro retablos a iniciativa de sus respectivas cofradías. En el lado del Evangelio el retablo de las Ánimas y el de la Virgen del Rosario, inicialmente ajustados en 1742 con el mismo Irazusta y continuados luego por sus oficiales. Parte de las esculturas que acogen estos dos primeros retablos han sido atribuidas, de nuevo fundadamente, a Carmona; el resto fueron hechas en 1757 por el escultor guipuzcoano Juan Bautista de Mendizábal. La construcción de los dos retablos del lado de la Epístola, uno dedicado a San Miguel y el otro a San Roque y San Sebastián, que debían levantarse de forma simétrica a los dos anteriores, se demoró algún tiempo debido a la penuria de sus cofradías. Fue por ello la propia parroquia la que tomó la iniciativa de levantarlos, siendo contratados con el tracista y arquitecto de retablos Tomás de Jáuregui en 1756. El de San Miguel, casi gemelo del de la Virgen del Rosario, tiene por titular una imagen atribuida también a Carmona, mientras que el resto de sus imágenes, los arcángeles Gabriel y Rafael, el Ángel de la Guarda y otra pareja más de ángeles, consta documentalmente que fueron contratadas con Juan Bautista de Mendizábal en 1757, además de una escultura de San Esteban destinada al ático del último retablo, el de San Roque y San Sebastián. Por la hechura de todo este conjunto de esculturas Mendizábal otorgaba carta de pago en marzo de 1758. Tres meses después quedaban policromadas por Antonio Jiménez. Por aquellos años Jáuregui y Mendizábal colaboraban asimismo en la construcción del retablo mayor de Zumárraga ${ }^{6}$.

Mantenedora del retablo de San Roque y San Sebastián era la cofradía del mismo nombre, establecida en la iglesia de Santa Marina en 1556. Confronta y hace pareja con el retablo de las Ánimas, a cuyo modelo se ajustó. Ambas máquinas, de gusto rococó, presentan un gran lienzo único en su cuerpo y una hornacina con escultura en el ático. Están bien documentados, como se ha visto, en cuanto a sus mazoneros y escultores, pero no así en cuanto a los autores de las pinturas. Dejando al margen la dedicada a las Ánimas, de calidad mediocre, centrémonos en el lienzo de San Roque y San Sebastián, objeto del presente artículo en sus dos versiones.

\footnotetext{
${ }^{4}$ Expreso mi agradecimiento a D. Jon Molina, párroco de la iglesia de Santa Marina de Oxirondo, por todas las facilidades dadas para llevar a cabo el trabajo de campo de esta investigación.

${ }^{5}$ Aramburu, 2008: I, 327-473. Anteriormente había ya aportado documentación al respecto Sagüés, 1973.

${ }^{6}$ Astiazarain, 1990. Sobre Juan Bautista Mendizábal véase también Zorrozua/Cendoya, 1990. Datan en 1744 su primera intervención documentada, en el retablo mayor de San Miguel de Idiazábal, y sitúa la fecha de su muerte en 1767, corrigiendo a Viñaza.
} 


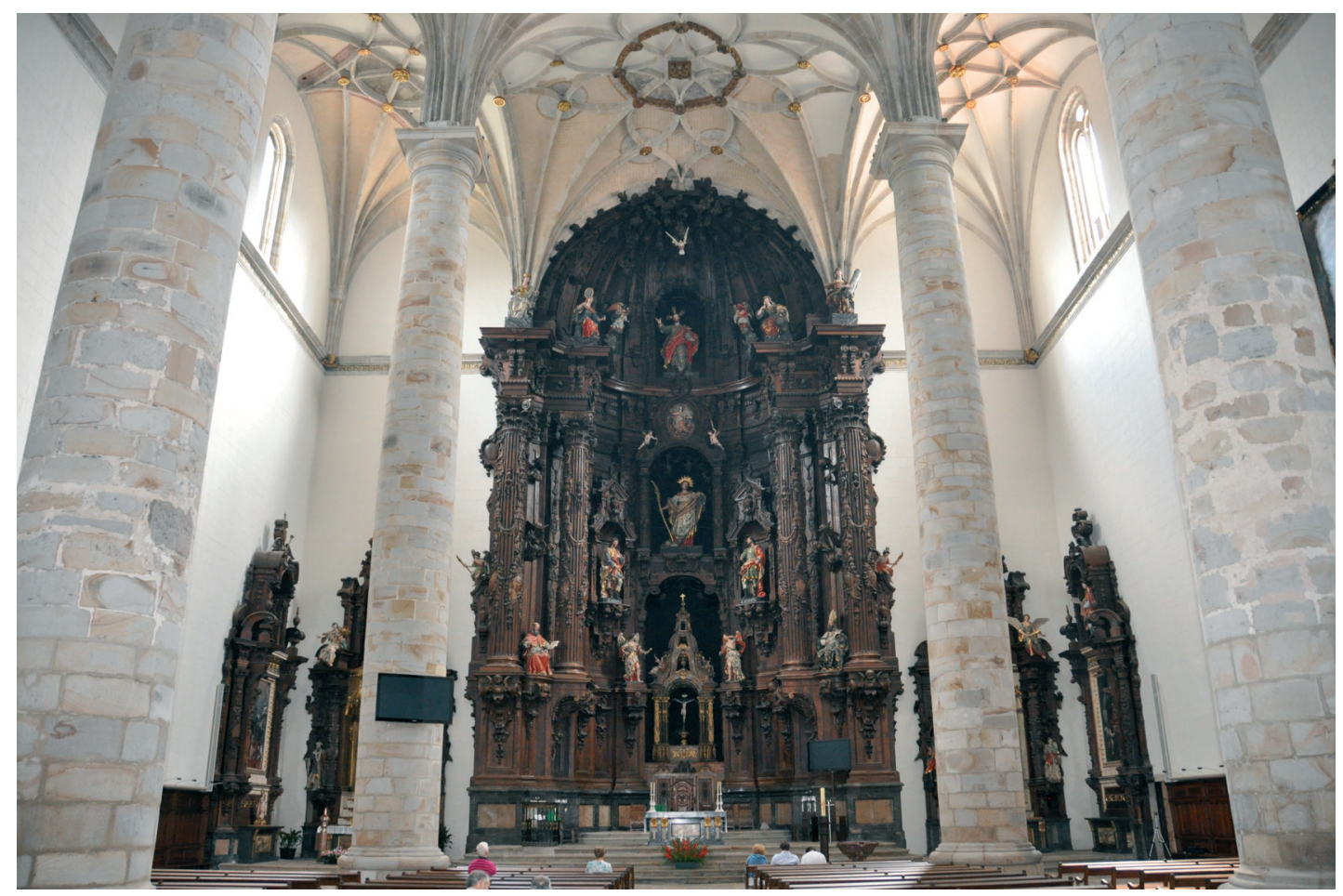

Fig. 1. Interior de la iglesia de Santa Marina de Oxirondo, Vergara (Guipúzcoa). Fotografía del autor.

\section{Conjeturas sobre el encargo a Bayeu}

Cierta tradición se había transmitido en Vergara de ser Francisco Bayeu el autor del lienzo titular del retablo de San Roque y San Sebastián. Aramburu, aunque proclive a descartarlo, advierte que, como en el caso de las esculturas de Luis Salvador Carmona, su encargo habría sido especial; y razona sagazmente que la otra versión del mismo tema que guarda la iglesia de Santa Marina habría sido hecha anteriormente por el mismo artista, pero con las medidas erróneas:

Los archivos no han ofrecido datos sobre la procedencia del cuadro, que sin duda fue encargado para este retablo. Tradicionalmente se cita una atribución a Bayeu sin que se hayan aportado datos ni ofrecido análisis alguno de la obra. No creemos que esta atribución se sostenga, ahora bien, la apreciable calidad de la pintura indica que no se trata de una producción local o comarcal. Con toda probabilidad se trata de una obra encargada a Madrid [...] en los años centrales del siglo XVIII; incluso es posible que inicialmente se encargara el otro cuadro que hemos citado, de tamaño algo menor, y que, al no encajar bien en el nuevo retablo, se hiciera un nuevo encargo al mismo pintor, pues ambos cuadros parecen de la misma mano ${ }^{7}$.

Hoy, gracias a las breves líneas que transcribimos de Ceán y al buen conocimiento que se tiene de la producción de Francisco Bayeu, podemos afirmar con total seguridad que ambos cuadros son de su mano y que tuvieron que ser realizados en las mismas fechas que la arquitectura del retablo, es decir, entre 1757 y 1758. Por aquellos años el joven Bayeu ya destacaba como el mejor pintor de Zaragoza, su ciudad natal, donde desarrolló una intensa actividad hasta su

\footnotetext{
7 Aramburu, 2008: I, 441-442.
} 
traslado a Madrid en 1763. Dicho esto, la primera cuestión que se suscita es por qué fue él el elegido, teniendo en cuenta que no hay constancia de otras obras suyas para el área vasconavarra ni sabemos de relaciones que pudiera haber cultivado en esas tierras, no excesivamente lejanas, hay que decirlo, de Aragón. Cabe en respuesta formular algunas hipótesis, acaso interrelacionadas entre sí. Una primera pone en juego a los escultores José Ramírez de Arellano y Juan Bautista Mendizábal. Ramírez de Arellano era en la década de 1750 el principal referente del arte escultórico en Aragón y mantenía vínculos muy estrechos con los pintores de su generación José Luzán y Juan Andrés Merclein, de quienes fue discípulo Bayeu. Por su parte Mendizábal, autor entre otras esculturas de Vergara del San Esteban del retablo de San Roque y San Sebastián, trabajó durante algún tiempo en Zaragoza con Ramírez, presumiblemente siendo aún joven ${ }^{8}$. No sería de extrañar que, ante el deseo de contar con un buen pintor, Mendizábal o personas próximas a él hubieran recabado el consejo de Ramírez. Como segunda hipótesis cabe considerar si la recomendación a Bayeu pudo venir del por entonces visitador general de la diócesis de Calahorra y La Calzada José Joaquín de Calatayud y Arellano, por sugerencia del dorador Juan Luzán, hermano de José Luzán, quien entre 1756 y 1757 realizó en colaboración con José Goya, padre de Francisco, trabajos de dorado en la catedral de Calahorra, de donde era canónigo el licenciado Calatayud ${ }^{9}$. Era, precisamente, el mismo visitador que en 1753 había autorizado dotar a la iglesia de Santa Marina de Oxirondo con los retablos de San Miguel y de San Roque y San Sebastián ${ }^{10}$. En esta red de relaciones y aunque las referencias cronológicas queden ahora algo alejadas, no está de más recordar que José Ramírez de Arellano hizo en 1769 las trazas y esculturas de los desaparecidos retablo mayor y colaterales del convento de carmelitas de Lesaca (Navarra) ${ }^{11}$, la misma localidad en cuya iglesia parroquial Tomás de Jáuregui había construido entre 1751 y 1754 su retablo mayor y dos colaterales, dotados con dos imágenes de Luis Salvador Carmona y el resto de Juan Bautista Mendizábal ${ }^{12}$.

En definitiva, no faltan razones para hablar de relaciones artísticas de carácter personal entre los distintos focos geográficos mencionados. Sea como fuere, lo más probable es que Bayeu llevara a cabo el trabajo en su taller zaragozano para luego ser enrollado y transportado a Vergara, práctica que era habitual. Esta circunstancia pudo propiciar el error cometido con las mediciones y que, en consecuencia, tuviera que repetir el cuadro ${ }^{13}$.

\section{Análisis de las dos pinturas}

En términos generales las dos versiones del San Roque y San Sebastián responden al que daremos en llamar estilo de "género mayor" que practicó el joven Bayeu en torno a los años 1755-1760, entendiendo por dicho estilo el que desarrolló en cuadros de gran formato, preferentemente de altar. Son pinturas de esmerado acabamiento que, aunque admiten toques fluidos, se contraponen a otras de formato menor y factura más suelta, bien fueran bocetos o cuadros reducidos. Dentro de ese "género mayor" son de obligada referencia las pinturas del retablo de San Rafael (habitualmente conocido como retablo de los Sagrados Corazones, iglesia parroquial de

“... trasladose a Zaragoza, en cuya ciudad trabajó con D. José Ramírez, haciendo progresos en el mal gusto de los adornos de retablos, y adquiriendo gran facilidad y manejo en devastar madera". Véase Viñaza, 1889-1894: III, 43.

9 "Visita realizada en 1753 por José Joaquín de Calatayud Arellano al Hospital de la villa de Escoriaza". En: http:// www.alava.net/arabadok/doc?q=arellano+calatayud\&start=1\&rows=1\&sort=score $\% 20 \mathrm{desc} \& \mathrm{fq}=$ msstored_archive $\& \mathrm{fv}$ $=* \& \mathrm{fq}=$ media $\& \mathrm{fv}=* \&$ father $=177397$ [14-1-2016]

10 Sagüés, 1973: 269.

11 García Gainza, 1973: 344. Fernández Gracia, 1985: 255-256.

12 García Gainza, 1971. Fernández Gracia, 2003: 464-467; 2008: 325-326.

13 He valorado la posibilidad de que se hubiera producido un malentendido entre los distintos sistema de medidas locales, teniendo en cuenta que la vara de Guipúzcoa medía $0,837 \mathrm{~m}$ (ligeramente mayor a la castellana) y la vara aragonesa $0,772 \mathrm{~m}$. Pero esta diferencia no es suficiente para justificar la excesiva variación de tamaño del primero al segundo lienzo. 
San Felipe, Zaragoza, 1755), La Inmaculada con alegorías de las Ciencias (Museo de la colegiata de Santa María de Calatayud), Santo Tomás de Aquino venciendo a los herejes (Museo de Zaragoza), Imposición del cinturón de castidad a Santo Tomás de Aquino (colegio de PP. Dominicos, Zaragoza) y La Sagrada Familia (iglesia parroquial de Bello, Teruel) ${ }^{14}$. Estas pinturas, al igual que las de Vergara, combinan sabiamente verosimilitud realista y elegante clasicismo. Hacen gala de cierta intensidad claroscurista, dando cabida a penumbras y brillos intensos. Recurren a una reducida pero armoniosa selección de impactos cromáticos principalmente materializados en los vivos colores que ostentan algunas vestiduras, cuyos plegados tanto blandos como aristados se conjugan de forma peculiar. Bayeu alcanzó con toda esa producción una calidad artística muy superior a la del resto de artistas de su entorno, por lo que no resulta fácil explicar su filiación respecto a quienes teóricamente le guiaron durante su primera formación, los pintores José Luzán y Juan Andrés Merclein, si bien cierto sentido claroscurista que en ocasiones presentan ambos y, sobre todo, la manera que tiene Merclein de realzar sus composiciones mediante el selectivo impacto de elementos de suntuoso colorido, podrían ayudar a justificar algunos aspectos particulares de la producción más temprana de Bayeu ${ }^{15}$. En cualquier caso son pinturas que muestran un apego significativo a la tradición barroca y que todavía no han desarrollado al máximo el potente influjo que Bayeu recibió de Antonio González Velázquez y, por su mediación, de Corrado Giaquinto; lo que hace pensar para todas ellas en unas fechas no posteriores a $1758^{16}$. Por el contrario, ese influjo renovador se revela con plenitud en obras como la Inmaculada (Palacio Arzobispal de Zaragoza, firmada en 1758), la Venida de la Virgen del Pilar (Londres, National Gallery, firmada en 1760) y La Trinidad en la gloria (Museo del Prado, boceto de presentación para un mural desaparecido del convento de Santa Engracia de Zaragoza), que acusan decididamente la presencia de modelos figurativos de estirpe "giaquintesca" y se decantan hacia una técnica más fluida de colores suaves y tornasoladas, con pérdida de monumentalidad y aminoramiento del naturalismo, caminando, en suma, hacia un gusto rococó más depurado. A partir de 1763, ya en Madrid y bajo la órbita de Mengs, Bayeu iniciaría nuevos caminos hacia una progresiva asimilación de la estética del idealismo clasicista.

Parece obvio que el primero de los dos cuadros que hizo Bayeu para Vergara fue el de dimensiones menores, el que no pudo ser destinado al retablo por ser de tamaño inferior al requerido (fig. 2). En él, las figuras protagonistas se yuxtaponen conformando una dinámica composición sinusoidal ascendente, determinada a la vez por varias diagonales. San Roque queda singularizado por su indumentaria de peregrino (bordón, esclavina con vieira prendida, sombrero de ala ancha) pero, sobre todo, por la herida de su pierna y el perro que asoma a sus pies. Junto a él, un angelito se ocupa tiernamente de su herida. Inmediatamente detrás, aunque sin conexión argumental, posa un típico San Sebastián semidesnudo atado a un árbol, contorsionado y asaeteado. La apretada amalgama de figuras se reafirma por efecto de la intensa iluminación lateral que las destaca sobre un apagado fondo paisajístico vespertino. El verde de la esclavina de San Roque y el azul del pequeño manto del ángel resaltan como toques de color puestos al servicio de una buscada sinfonía cromática. La veracidad expresiva y gestual de los personajes, junto con su representación naturalista no exenta de elegancia, son distintivos inequívocos del primer Bayeu, ya en pleno dominio de su oficio. En relación a las varias obras de Bayeu antes mencionadas, una particular analogía a destacar es la cabeza del ángel que asiste a San Roque respecto a la cabeza también angélica situada a la derecha del lienzo del Corazón de Jesús del retablo de San Rafael, ambas cabezas de corta melena con flequillo alborotado, nariz respingona, ojo rasgado y

${ }^{14}$ Sobre la producción juvenil de Francisco Bayeu y estas obras en particular véanse, entre otros: Morales, 1995. Ansón, 1996; 2007. Calvo, 2010. Lozano, 2011. Ansón, 2012. Jimeno, 2013.

15 Es un argumento a favor de aceptar que Bayeu, además de convertirse en yerno de Merclein en 1759 por su matrimonio con Sebastiana, hubiera con anterioridad recibido enseñanzas suyas, tal y como afirma Viñaza, 1889-1894: III, 44, al decir que dicha hija "casó con el ilustre pintor D. Francisco Bayeu, de quien fue también Merclein su primer maestro". Al no hacer Ceán mención de tal magisterio, Ansón, 1996: 9, cuestiona que tuviera lugar.

${ }^{16}$ Las precisiones cronológicas hasta ahora propuestas para las obras no documentadas del período zaragozano de Francisco Bayeu están sujetas a incertidumbre. 


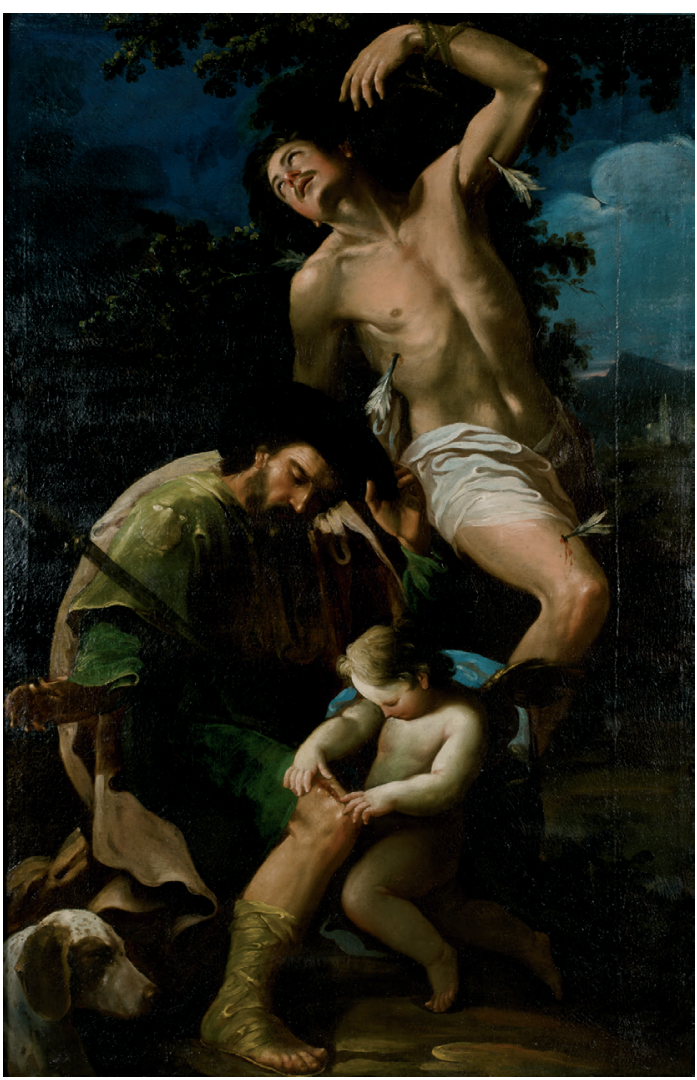

Fig. 2. Francisco Bayeu, San Roque y San Sebastián, ca. 1757-1758. Iglesia de Santa Marina de Oxirondo, Vergara (Guipúzcoa). Fotografía Fundación Ibercaja.

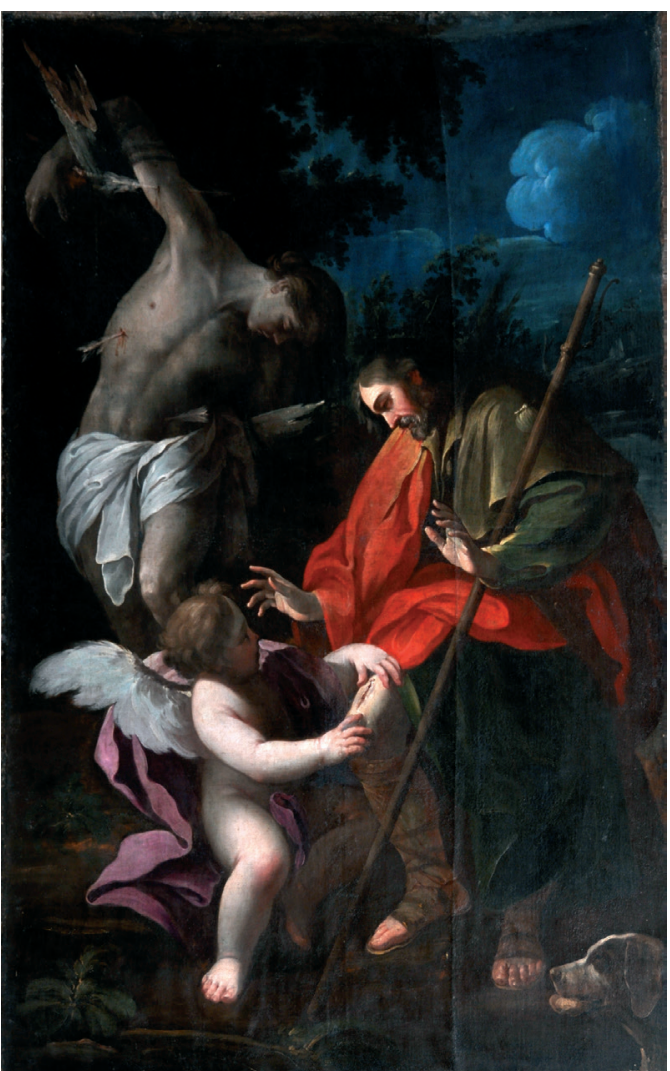

Fig. 3. Francisco Bayeu, San Roque y San Sebastián, ca. 1757-1758. Lienzo titular de su retablo en la iglesia de Santa Marina de Oxirondo,

Vergara (Guipúzcoa). Fotografía del autor.

frente resuelta mediante una luminosa mancha en forma de media luna. Compárese asimismo la analogía del rostro escorzado de San Sebastián, de mirada arrobada, con el de Santo Tomás del Museo de Zaragoza. La pose de San Roque, en fin, tiene claro parangón con la de Santiago en la Venida de la Virgen del Pilar (Londres, National Gallery), cuya filiación con otras figuras de González Velázquez y Giaquinto es bien conocida. El cuadro lleva un marco de época, dorado y marmoleado en tonalidades azules.

En el segundo cuadro (fig. 3), el definitivo hecho para el retablo (fig. 4), lejos de demostrar desgana o simple comodidad en repetir el mismo tema, Bayeu nos sorprende con una nueva versión que modifica notablemente la composición y gana en perfección y exquisitez, haciendo gala de un rasgo de su personalidad que fue notorio no sólo a lo largo de su obra sino también de su trayectoria humana, el afán de superación, el perfeccionismo. No pasa por alto una cierta disminución del protagonismo de San Sebastián, ahora en discreta penumbra y algo menguado, como si hubiera querido asignarse un papel más principal a San Roque. El esquema compositivo formado por las tres figuras se ajusta a una articulación más geométrica y serena, que no rígida, pero dominada asimismo por líneas diagonales. Aumenta el apurado de la pincelada y los contrastes lumínicos otorgan mayor rotundidad a los personajes. Las tintas, más fuertes, ofrecen una particular sinfonía a través del malva, rojo y verde de los paños. Las carnaciones alcanzan calidades un tanto nacaradas. Artificios todos ellos que no impiden el palpitante verismo expresivo que la pintura transmite. Parece hacerse eco, por vía directa o indirecta, de algunas propuestas de Giaquinto si lo comparamos con ciertas obras del maestro napolitano afectadas de un mayor 
clasicismo como su Venus y Cupido de hacia 1754, cuyo lustre esmaltado e intenso efecto lumínico están al servicio de una exquisita delicadeza. La potencia del sombreado trae recuerdos de otros artistas napolitanos como Francesco Solimena ${ }^{17}$, cuyas sugerencias cabe pensar si pudo Luzán transmitirlas a sus discípulos años después de su vuelta de Nápoles, aunque a él no parece que le hicieran mucha mella.

Hay detalles particulares del segundo San Roque y San Sebastián que nos remiten a algunas pinturas de Bayeu del período zaragozano. Con el Santo Tomás de los Dominicos de Zaragoza comparte cierto paralelismo compositivo y destaca, sobre todo, la afinidad del angelito que acompaña a San Roque con el que lleva un libro en el cuadro dominicano. El rostro sereno y de mirada absorta de San Roque recuerda al de Cristo en el boceto para el desaparecido mural del monasterio de Santa Engracia de Zaragoza (Museo del Prado). El grafismo de las nubes borrascosas, densificado en algunos contornos y diluido en otras zonas, es recurrente en los cuadros del Vía crucis y de Santo Tomás del Museo de Zaragoza, en la Inmaculada de Calatayud o en la Sagrada Familia de Bello. Hay matorrales en el suelo poco convencionales, como si reprodujeran especies concretas, al igual que los de Calatayud y Bello.

En definitiva, estamos ante dos obras típi-

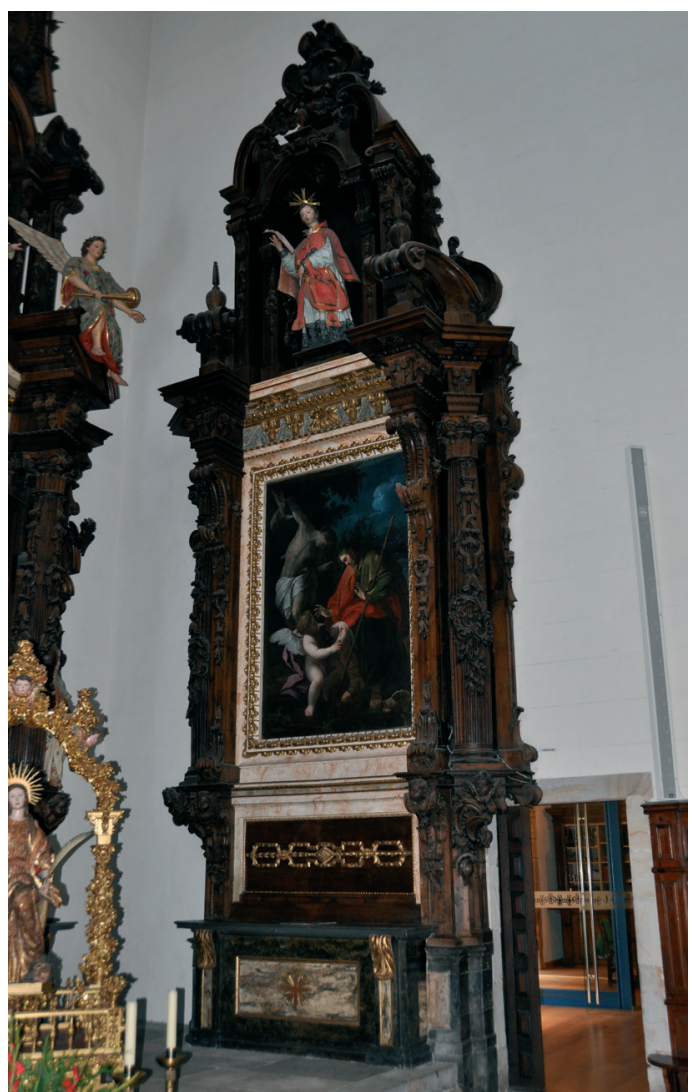

Fig. 4. Retablo de San Roque y San Sebastián, 17571758. Iglesia de Santa Marina de Oxirondo, Vergara (Guipúzcoa). Fotografía del autor. cas de lo que fue la producción más temprana de Francisco Bayeu, en las que a pesar de su juventud se nos revela como un pintor afianzado en un oficio excelente. Por su contundencia cromática y lumínica, por el regusto naturalista y por los complejos recursos compositivos utilizados, denota un apego cierto a la tradición barroca, a la que en los años cincuenta del siglo todavía eran muy afectos algunos artistas locales ya veteranos como Pablo Félix Rabiella o, en buena medida, Juan Andrés Merclein. Pero también sabe imbuirse de un elegante aire clasicista, a la vez que empieza a interesarse por ciertos modelos figurativos y por una técnica de brillos y empastes fluidos que delatan el influjo de González Velázquez y sus postulados "giaquintistas", a los que acabaría rendido en su etapa final zaragozana.

Un último comentario resta por hacer concerniente a la anotación "1780" de la ficha de Ceán antes transcrita. Aunque su interpretación más obvia sería que quisiera referirse al año de realización de los lienzos de Vergara, existen argumentos suficientes para reafirmar, tal y como se ha razonado, que la cronología que más les conviene es la de 1757-1758. Es, en consecuencia, una anotación de incierto significado.

17 En pinturas de Solimena como Diana y Endimión (Walker Art Gallery, Liverpool) observamos un refinado sentido descriptivo, un resuelto claroscurismo y unos potentes componentes cromáticos que se nos hacen familiares en los cuadros de Vergara. 


\section{BIBLIOGRAFÍA}

Ansón Navarro, Arturo (ed.) (1996): Francisco Bayeu. 1734-1795. Zaragoza: Ibercaja.

Ansón Navarro, Arturo (ed.) (2007): Francisco Bayeu y sus discípulos. Zaragoza: Cajalón.

Ansón Navarro, Arturo (2012): Los Bayeu, una familia de artistas de la Ilustración. Zaragoza: Caja Inmaculada.

Aramburu, María José (2008): Arte y piedad. El arte religioso en Bergara en la Edad Moderna. Bergara: Ayuntamiento de Bergara, 2 vols.

Astiazarain Achabal, María Isabel (1990): "El arquitecto Tomás de Jáuregui y el escultor Juan Bautista Mendizábal en el Retablo Mayor de Zumárraga". En: Boletín de la Real Sociedad Bascongada de los Amigos del País, XLVI, 3-4, San Sebastián, pp. 359-397.

Calvo Ruata, José Ignacio (2010): "El factor Bayeu en la formación de Goya”. En: Artigrama, 25, Zaragoza, pp. 21-51.

Calvo Ruata, José Ignacio (2015): “Goya y los artistas de Zaragoza”. En: Mena Marqués, Manuela B. (ed.) (2015): Goya y Zaragoza, 1746-1775. Sus raices aragonesas. Zaragoza: Ibercaja, pp. 47-70.

Fernández Gracia, Ricardo (1985): “Contribución a la obra de José Ramírez en Navarra”. En: El Arte Barroco en Aragón. Actas III Coloquio de Arte Aragonés. Huesca, 19-21 diciembre 1983. Sección I. ${ }^{a}$. Huesca: Diputación Provincial de Huesca, pp. 249-262.

Fernández Gracia, Ricardo (2003): El retablo barroco en Navarra. Pamplona: Gobierno de Navarra.

Fernández Gracia, Ricardo (2008): "Reflexiones sobre el arte foráneo en Navarra, durante los siglos del Barroco". En: Cuadernos de la Cátedra de Patrimonio y Arte Navarro, 3, Pamplona, pp. 295-339.

García Gainza, María Concepción (1971): "Los retablos de Lesaca. Dos nuevas obras de Luis Salvador Carmona". En: Homenaje a don José Esteban Uranga. Pamplona: Aranzadi, pp. 327-363.

García Gainza, María Concepción (1973): "El convento de carmelitas descalzas de Lesaca". En: Boletín del Seminario de Estudios de Arte y Arqueología, XXXIX, Valladolid, pp. 333-344.

Jimeno, Frédéric (2013): "Une ouvre inédite de Francisco Bayeu. Un nouveau regard sur la fortune de Diego Velasquez dans l'Espagne des Lumières". En: http://www.ghamu.org/spip.php?article424 (febrero 2016).

Lozano López, Juan Carlos (2011): “Aportaciones documentales sobre el retablo de San Rafael (o de los Sagrados Corazones) en la iglesia de San Felipe y Santiago el Menor de Zaragoza”. En: Aragonia Sacra, XXI, Zaragoza, pp. 227236.

Morales y Marín, José Luis (1995): Francisco Bayeu. Vida y obra. Madrid: Moncayo.

Sagüés Subijana, Miguel (1973): "Cuatro retablos barrocos guipuzcoanos”. En: Boletín de la Real Sociedad Vascongada de los Amigos del País, XXIX, $1 .^{\circ}-3$. $^{\circ}$, San Sebastián, pp. 235-271.

Viñaza, Conde de la [Muñoz Manzano, Cipriano] (1889-1894): Adiciones al Diccionario Histórico de los más ilustres profesores de las Bellas Artes en España de D. Juan Agustín Ceán Bermúdez. Madrid, 4 vols.

Zorrozua Santisteban, Julen/Cendoya Echániz, Ignacio (1990): "Precisiones sobre los Mendizábal, escultores guipuzcoanos del siglo XVIII. Nuevas obras en Bizkaia y Gipuzkoa”. En: Kobie (Serie Bellas Artes), VII, Bilbao, pp. 5-24.

Fecha de recepción: 02-II-2016

Fecha de aceptación: 19-VII-2016 